\title{
RAISING SELF-CONCEPT AND INTEREST FOR STATISTICS THROUGH ACTIVITY- BASED INSTRUCTION
}

\author{
Ute Sproesser $^{1}$, Joachim Engel ${ }^{2}$, Sebastian Kuntze ${ }^{2}$ \\ ${ }^{1}$ Heidelberg University of Education, Germany \\ ${ }^{2}$ Ludwigsburg University of Education, Germany \\ engel@ph-ludwigsburg.de
}

Instructional methods involving students in activities have been recognized to be a pedagogically highly valuable approach to teaching statistical concepts. This approach is rooted in concepts of modern pedagogy emphasizing student's activities in problem solving situations. We report about an intervention study to provide empirical evidence to the claimed motivational benefits of learner centered activities as a method to teach statistical concepts. Motivational variables such as selfconcept and specific interest in statistics were measured before and after activity-based interventions extending over four 45 minute classroom periods. Data about these motivational variables and - as comparison - corresponding variables related to mathematics were gathered from 450 eighth graders before and after the intervention. Our results confirm that statisticsrelated self-concept and interest is distinct and can be fostered through the intervention.

\section{THEORETICAL BACKGROUND}

Motivational variables such as self-concept and interest accompany the learning process and influence learners' achievement development in and beyond school (e.g.. Eccles \& Wigfield, 2002; Jacobs, Lanza, Osgood, Eccles, \& Wigfield, 2002). Therefore the development of students' motivational variables is recognized as an important goal of schooling (O'Mara, Marsh, Craven \& Debus, 2006; Schiefele, 1991). However, only a few studies have investigated these variables in the context of learning statistics, even less with a quasi-experimental intervention design.

Activity-based methods have been recognized to be a pedagogically highly valuable approach to teaching statistical concepts (e.g. Engel, 2002; Erickson, Scheaffer, Gnanadesikan, Watkins \& Witmer, 2004; Rossman, 2011). This approach is rooted in concepts of modern pedagogy emphasizing student's activities in problem solving situations. Students learn mathematics and statistics with understanding when they actively build new knowledge from experience and prior knowledge. To develop a good conceptual understanding of statistics students are likely to profit from hands-on experience with data collection and data analysis. In this study, we investigated within a quasi-experimental design if interest and self-concept related to statistics can be supported through a short intervention based on several activity-based statistics tasks.

\section{Self-concept}

The term self-concept describes an individual's beliefs about the own abilities in a distinct academic or non-academic domain (e.g. Bong \& Skaalvik, 2003). For instance, mathematics related self-concept expresses a person's confidence in his or her competencies concerning this particular domain. Such domain-specific self-concept can be expected to be positively correlated to achievement in the corresponding domain (Eccles \& Wigfield, 2002), as, for instance, a positive academic self-concept often leads to initializing and maintaining success-oriented behaviors. The relationship between self-concept and learning is the reason why several studies have aimed at supporting this motivational variable. A meta-analysis of O'Mara et al. (2006) revealed that interventions focusing on praise and feedback but also on fostering domain-specific skills have shown to be successful in supporting academic self-concepts.

\section{Interest}

Schiefele (1991, p. 302) defines individual interest as a "relatively enduring preference for certain topics, subject areas, or activities". This definition implies that interest constitutes a relationship between an individual and a specific content, thus - like self-concept - interest is a domain-specific variable. According to Schiefele, individuals attribute a personal relevance to their targets of interest (value-related valences). Moreover, interest usually is accompanied by involvement and enjoyment (feeling-related valences). Therefore, an interested individual engages

In: M.A. Sorto (Ed.), Advances in statistics education: developments, experiences and assessments. Proceedings of the Satellite conference of the International Association for Statistical Education (IASE), July 2015, Rio de Janeiro, Brazil. 
in an activity or subject for its own sake and strives to learn about it. As interested students are more likely to employ meaning-oriented learning activities, elaborated learning strategies and report a higher appreciation of their learning experience, interest may also improve achievement (ibid.). Results from Hidi and Renninger (2006) indicate that students' interest may be supported by providing helpful feedback, choosing challenging tasks, enabling social learning and promoting the experience of autonomy.

\section{Self-concept and interest related to mathematics and statistics}

In the domain of mathematics, motivational variables have been examined by a large number of studies: For instance Baumert and Köller (2000) report that achievement is correlated to self-concept $(r=.73)$ and interest $(r=.69)$. Referring to statistics, only a few studies have examined motivational variables..Within post-secondary education, Emmioglu and Capa-Aydin (2012) report positive relationships between achievement and motivational variables from a metaanalysis. Concerning secondary students, Carmichael, Callingham, Hay and Watson (2010) found significant correlations between self-concept and interest in statistics and prior mathematics achievement. In any case, Gal, Ginsburg and Schau (1997) advise researchers to discriminate between students' perceptions of statistics and mathematics because of their proximity.

\section{A student-centered intervention based on statistics tasks}

The intervention addressed different aspects of statistics: The students worked on basic tasks including dealing with tables, diagrams or characteristic values in different contexts. For instance, learners were requested to investigate the color distribution of chocolate lentils. Apart from basic tasks (e.g. "Compute the average number of yellow chocolate lentils from 10 packages"), the intervention also involved considerations of statistical variation (e.g. "Compare your average of yellow chocolate lentils with your partner's average. Why are they not identical?") and data reduction ("Computing the average deletes information from your data. What detail information about your packages of chocolate lentils has got lost?").

The student-centered learning material encompassed hands-on activities in contexts that are relevant for $8^{\text {th }}$-graders, hence they were designed to be of interest for the students of our sample. During the intervention, students worked in pairs on the statistics-related problems with the opportunity to get help from flash cards and to compare their responses with sample solutions. After each topic, the students were given additional individual feedback about their work. The design of the intervention took into account several studies which have shown that student-centered learning environments providing feedback and autonomy in cooperative learning situations can support motivational variables (e.g. Hattie, Biggs, \& Purdie, 1996).

Consequently, the intervention was designed to have both an impact on students' competency related to statistics and on motivational variables.

\section{RESEARCH QUESTIONS}

- Are mathematics- and statistics-related self-concept and interest empirically separable?

- Can students' domain-specific self-concept and interest be fostered through a short activitybased intervention?

\section{METHOD}

Data from 450 German eighth graders between 12 and 15 years (M 13.50, SD 0.62) was analyzed. These students from 25 classes in eight German technical-track secondary schools participated in the intervention (four 45-minute classroom lessons) as well as in pre- and posttest. The intervention consisted of learner-centered hands-on activities including analyzing bags with differently colored candies (Molesky \& Tyson, 2013), data from paper airplane experiments (Shuttleworth, 2005) and waiting times for geyser eruptions (Shaughnessy \& Pfannkuch, 2002) engaging students in data summaries, constructing and analyzing graphs and evaluating sample variability. A non-intervention group of 53 eight-graders (aged between 13 and 15 years, M 13.73, SD 0.72) served as control group. In the pretest there were no significant differences between control group and intervention group in their statistics-related self-concept and interest. 
Before and after the intervention, motivational dispositions referring to mathematics and statistics were assessed using a 5-point Likert scales. Mathematics-related self-concept and interest (6 items per scale) was measured through scales established by Pekrun, Götz, Jullien, Zirngibl, v. Hofe \& Blum (2002). Students' statistics-related self-concept and interest (3 items per scale) were tapped with instruments adapted by Gundlach, Kuntze, Engel and Martignon (2010). In addition three tasks related to tables, bar charts and characteristic values were presented to the learners. We asked them how confident they felt about being able to solve these tasks and about their interest in them. Students' ratings were summarized in a scale for self-concept and a scale for interest in these specific tasks ("task-specific self-concept/interest"). These scales enabled us to compare students' ratings of the task-specific and non-task-specific statistics-related scales and hence to evaluate whether they associated the term statistics with dealing with statistical contents such as presented in the tasks. Some sample items are displayed in Table 1.Table 1: Sample questions

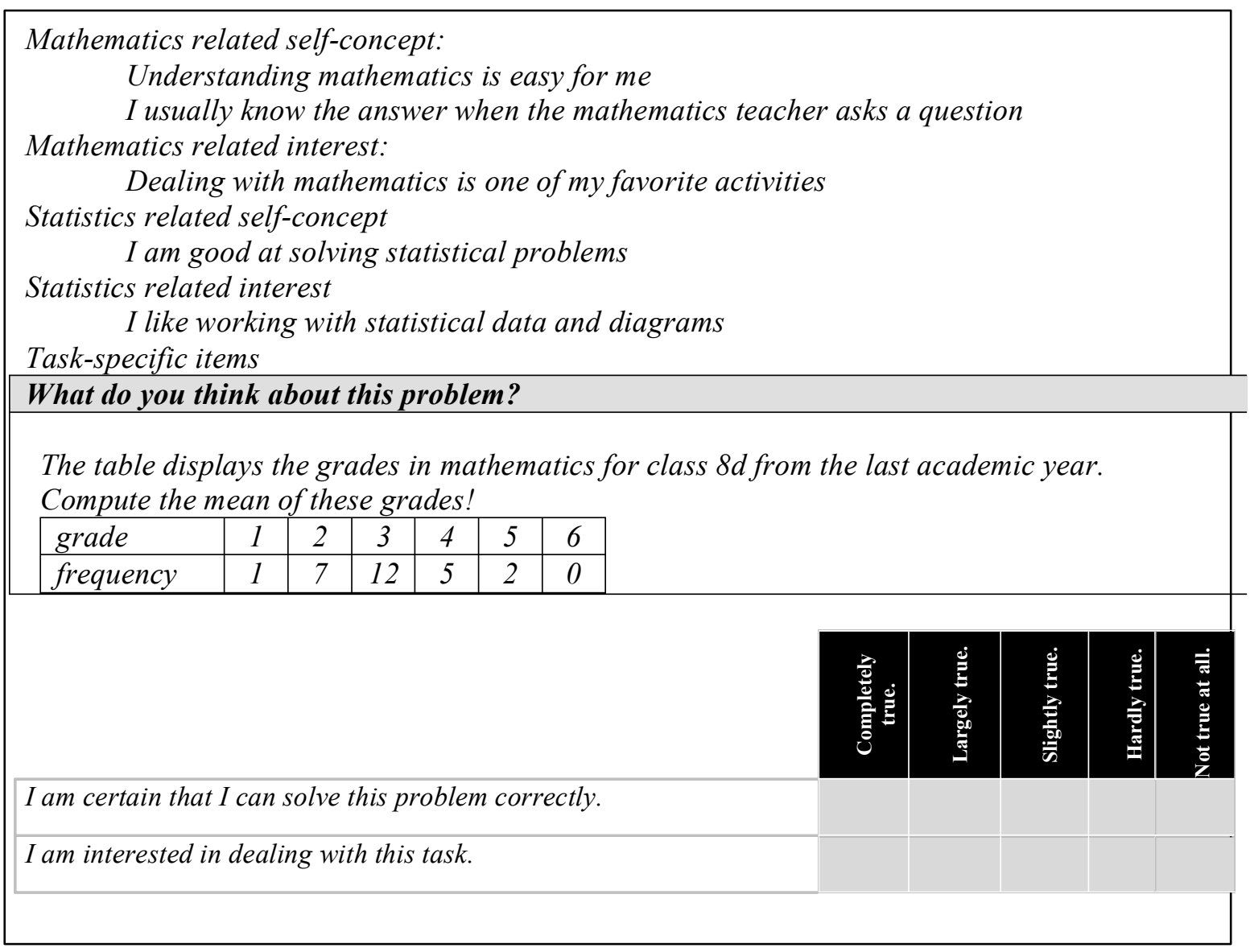

\section{RESULTS}

Following the advice of Gal et al. (1997), we first investigated whether the mathematicsand statistics-related scales were empirically separable within our sample. For this purpose, we included the items for mathematics- and statistics-related self-concept and interest into a confirmatory factor analysis and examined whether mathematics-related scales were empirically separable from statistics-related items within our sample.

Global fit indices indicate that the model fits the data reasonably well $\left(\chi^{2} / \mathrm{df}=2.33\right.$, recommended $\leq 5$ by Bollen $\&$ Long, 1993; CFI $=0.97$, recommended $\geq 0.95$ by Hu $\&$ Bentler, 1999; RMSEA $=0.05$, recommended $\leq 0.06$ by $\mathrm{Hu} \&$ Bentler, 1999). Model comparisons (chisquare tests performed on the AICs) between this model and superordinate models further confirm the appropriateness of this model. Local fit indices suggest that the latent variables were reliably measured by the corresponding items and that each variable was discriminable from the other ones (indicator reliabilities $\geq 0.3$; factor loadings statistically significant; factor reliabilities $r \geq 0.85$; average variance extracted $\geq 0.66$; Fornell-Larcker-Criterion met). 
Figure 1 displays the parameter estimates and the structure of the confirmatory factor analysis: the four scales mathematics- and statistics-related self-concept and interest turned out to be separable factors despite latent intercorrelations of .53 to .77 . The analysis of the posttest showed similar results.

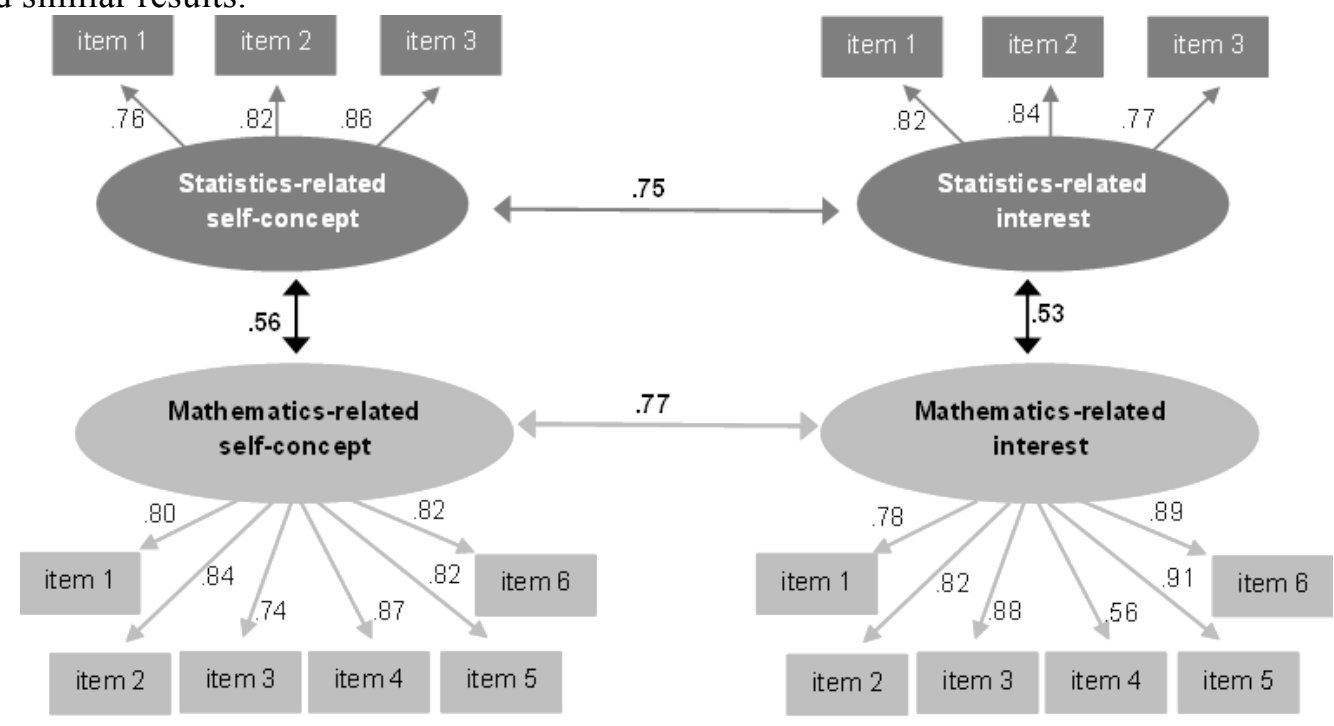

Figure 1: Confirmatory factor analysis for the pretest

Research question 2 focused on investigating whether the means of domain-specific selfconcept and interest significantly increased due to the intervention. The corresponding significance tests were conducted with Mplus 7.1: We specified regression models predicting self- concept /interest in the posttest by the corresponding pretest values and by the group assignment (posttest $=$ $\beta_{0}+\beta_{1} \cdot$ pretest $+\beta_{2} \cdot$ group $+\varepsilon$ ). This procedure allowed us to evaluate if the increase of self-concept and interest in the intervention group was significant compared to the control group, hence to examine if effects could be attributed to the intervention. Including the pretest scores in the regressions controls for potential differences in the initial values between the groups.

As displayed in Figure 2, the means of the mathematics-related scales barely differed from pre- to posttest in the intervention group. Although the difference concerning interest in mathematics was significant for the intervention group compared to the control group, the effect sizes for both mathematics-related scales were small. Concerning the domain of statistics, selfconcept and interest increased significantly in the intervention group with a small to a medium effect size as measured by Cohen's d. Task-specific self-concept and interest (reliabilities from 0.67 to 0.94 ) also increased significantly from pre- to posttest with relevant effect sizes. At the same time, the absolute means of these scales were higher than for the non-task-specific scales for statistics-related self-concept and interest.

Pearson correlations between the statistics-related task-based and non-task-based selfconcept scales were $r=.47(\mathrm{p}<.001)$ for the pretest and $\mathrm{r}=.48(\mathrm{p}<.001)$ for the posttest. Concerning statistics-related task-based and non-task-based interest scales, correlations were even higher (pretest: $\mathrm{r}=.57, \mathrm{p}<.001$; posttest: .66, $\mathrm{p}<.001$ ). These correlations suggest that students associated the domain of statistics with tasks such as the presented ones, referring to tables, bar charts and characteristic values. 

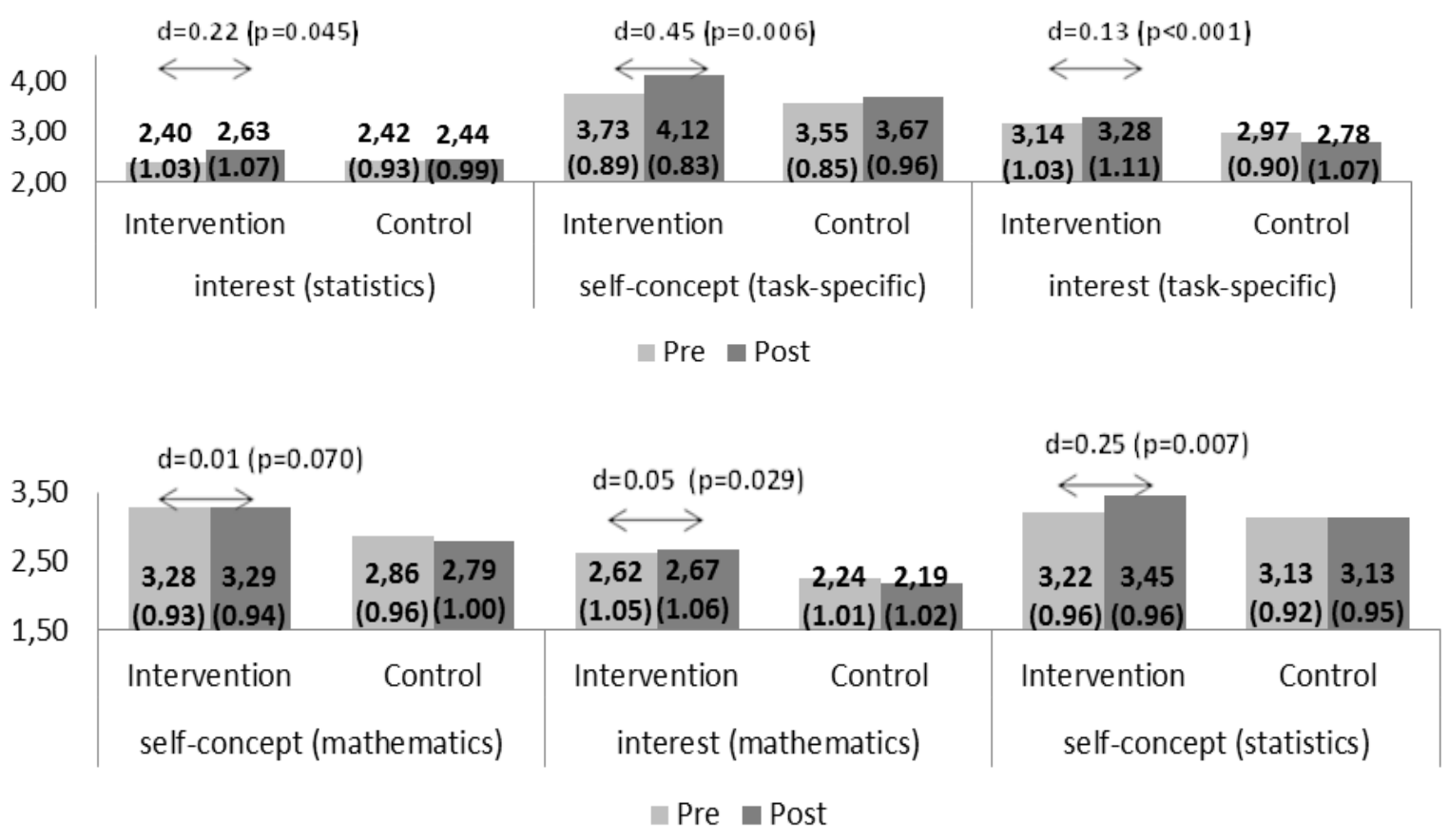

Figure 2: Development of students' self-concept and interest

\section{IMPLICATIONS FOR THEORY AND PRACTICE}

Our results imply that the students perceived mathematics and statistics differently from a motivational point of view. It further confirms that it is reasonable to evaluate these motivational variables for statistics separately from those related to mathematics. However, latent correlations of about 0.5 emphasize the relatedness between these two domains. Furthermore, the magnitudes of latent correlations between self-concept and interest were as expected from the literature and underline the proximity of these variables.

The second research question evaluated if students' domain-specific self-concept and interest could be supported through a statistics-oriented intervention. As the intervention referred specifically to statistics, our findings conform to the expectation that mathematics-related selfconcept and interest remain relatively stable. This can be considered as a further indicator of the validity of the measures.

Concerning general statistics-related and task-specific self-concept and interest, we observed a significant increase with relevant effect sizes in the course of the intervention. Hence, it appears that providing statistics-specific hands-on activities, cooperative learning, student-centered work and feedback in the learner-centered intervention helped to foster students' self-concept and interest. Moreover, as there was exclusively a relevant increase concerning the statistics-related scales, it appears that the combination of the properties of the learning environment and the focus on the domain of statistics has led to this increase. This implies for the educational practice that students' self-concept and interest related to the domain of statistics can be fostered by working on statistical problems in an appropriate classroom setting such as an environment that uses hands-on activities.

\section{ACKNOWLEDMENTS}

This study was supported by research funds of Ludwigsburg University of Education and by the Ministry of Science, Research and the Arts Baden-Württemberg, Germany. 


\section{REFERENCES}

Baumert, J., \& Köller, O. (2000). Unterrichtsgestaltung, verständnisvolles Lernen und multiple Zielerreichung im Mathematik- und Physikunterricht der gymnasialen Oberstufe. In J. Baumert, W. Bos \& R. Lehmann (Eds), TIMSS III. Dritte Internationale Mathematik- und Naturwissenschaftsstudie (pp. 271-316) Opladen: Leske und Budrich.

Bong, M., \& Skaalvik, E. M. (2003). Academic self-concept and self-efficacy: how different are they really? Educational Psychology Review, 15(1), 1-40.

Carmichael, C., Callingham, R., Hay, I \& Watson, J. (2010). Statistical literacy in the middle school: The relationship between interest, self-efficacy and prior mathematics achievement. Australian Journal of Educational \& Developmental Psychology, 10(1), 83-93.

Eccles, J.S., \& Wigfield, A. (2002). Motivational Beliefs, Values, and Goals. Annual Review of Psychologie 53, 109-132.

Emmioglu, E. \& Capa-Aydin, Y. (2012). Attitudes and achievement in statistics: A meta-analysis Study. Statistics Education Research Journal, 11(2), 95-102.

Engel, J. (2002). Activity-based statistics, computer simulation and formal mathematics. In B. Phillips (Ed.), Proceedings of the Sixth International Conference on Teaching of Statistics, Cape Town. Voorburg, The Netherlands: International Statistical Institute. Retrieved May 7, 2015 from https://www.stat.auckland.ac.nz/ iase/publications/1/5a3_enge.pdf

Erickson, T., Scheaffer, R., Gnanadesikan, M., Watkins, A., \& Witmer, J. (2004). Activity-based statistics (2nd Edition), Emeryville, CA: Key College.

Gal, I., Ginsburg, L., \& Schau, C. (1997). Monitoring attitudes and beliefs in statistics education. In I. Gal \& J. B. Garfield (Eds.), The assessment challenge in statistics education (pp. 37-51). Amersterdam: IOS Press.

Gundlach, M., Kuntze, S., Engel, J., \& Martignon, L. (2010). Motivation and self-efficacy related to probability and statistics: Task-specific motivation and proficiency. In C. Reading (Ed.), Data and context in statistics education: Towards an evidence-based society. Proceedings of the $8^{\text {th }}$ Int. Conf. on Teaching Statistics. Voorburg, The Netherlands: ISI. Retrieved May 7, 2015 from http://iase-web.org/documents/papers/icots8/ICOTS8_C157_GUNDLACH.pdf

Hattie, J., Biggs, J. B., \& Purdie, N. (1996). Effects of learning skills interventions on student learning: A metaanalysis. Review of Educational Research, 66(2), 99-136.

Hidi, S. \& Renninger, K.A. (2006). The four-phase model of interest development. Educational Psychologist, 41(2), 111-127.

Jacobs, E.J., Lanza, S., Osgood, D.W., Eccles, J.S., \& Wigfield, A. (2002). Changes in children's self-competence and values: gender and domain differences across grades one through twelve. Child Development. 73(2), 509-527.

Molesky, J., \& Tyson, D. (2013). M\&M statistics activities. NCTM National Conference, Denver. Retrieved May 7, 2015 from http://apstatsmonkey.com/StatsMonkey/m\%26m_Activities.html

O’Mara, A.J., Marsh, H.W., Craven, R.G., \& Debus, R.L. (2006). Do self-concept interventions make a difference? A synergistic blend of construct validation and meta-analysis. Educational Psychologist, 41(3), 181-206.

Pekrun, R., Götz, Jullien, S., Zirngibl, A., v. Hofe, R., \& Blum, W. (2002). Skalenhandbuch PALMA: 1. Messzeitpunkt. Universität München: Institut Pädagogische Psychologie.

Rossman, A., \& Chance, B. (2011). Workshop Statistics. Discovery with Data. (4th Edition), Wiley: New York.

Schiefele, U. (1991). Interest, learning, and motivation. Educational Psychologist, 26(3\&4), 299323.

Shaughnessy, M. \& Pfannkuch, M. (2002). How faithful is Old Faithful? statistical thinking: A story of variation and prediction. Mathematics Teacher, 95(4), 252-259.

Shuttleworth, M. (2008). Paper airline experiment. Retrieved May 7, 2015, from https://explorable.com/paper-airline-experiment. 